\title{
IMPLANTAÇÃO DE PROGRAMA DE QUALIDADE DE VIDA
}

\author{
Latorre $\mathrm{TAMH}^{1}$, Paternes $\mathrm{KC}^{2}$ \\ 1. Assistente Administrativo responsável pela área de Gestão de Desenvolvimento de Pessoas no Instituto de Radiologia do HCFMUSP/InRad \\ 2. Assessor Técnico responsável pelo Centro de Gestão de Pessoas no Instituto de Radiologia do HCFMUSP/InRad
}

\section{Introdução}

O Instituto de Radiologia estabeleceu a partir do levantamento do perfil epidemiológico dos colaboradores um Programa de Qualidade de Vida. Entendemos que este aspecto faz parte do escopo de qualquer organização, pois reflete no clima organizacional, bem como na retenção de pessoal.

Este processo contribui para o resultado global dos processos de Gestão de Pessoas (agregar, aplicar, recompensar, manter, desenvolver e monitorar). Compreendendo a percepção individual de bem-estar, sustentada pelo equilíbrio do tripé biopsicossocial(1), o Instituto de Radiolgia agrupou e desenvolveu atividades relacionadas aos Eixos Temáticos: Atividade Física, Responsabilidade Socioambiental e Saúde e Segurança.

\section{Objetivo}

Engajar os funcionários nas ações de qualidade de vida institucionalizada e aumentar a adesão nos treinamentos, ações de saúde e segurança ocupacional.

\section{Materiais e Métodos}

Através de dados referentes ao perfil epidemiológico dos colaboradores, participação nas ações oferecidas pelo grupo técnico de humanização e baixa adesão aos treinamentos legais foi elaborado o Programa de Qualidade de Vida classificado por atividades em eixos temáticos: Atividade Física, Responsabilidade Socioambiental e Saúde e Segurança.

Foi divulgado regulamento informando quais ações fariam parte do programa, qual a frequência para conseguir a pontuação e passaporte com atualização mensal através de carimbo com base na participação das ações. Criou-se a hashtag InRad_ação, permitindo comentar, compartilhar e curtir o conteúdo publicado e campanhas motivacionais.

Estabeleceu-se a gestão do processo com a criação e manutenção da planilha de controle de participação, subsidiando o acompanhamento por meio de indicadores.

\section{Resultados}

O acompanhamento das atividades realizadas no período de maio a novembro de 2018 possibilitou a composição e divulgação do ranking de participação e entrega de prêmios para os 35 colaboradores melhores pontuados.

\section{Conclusão}

Essa metodologia trouxe maior adesão às atividades oferecidas pelo instituto, além da possibilidade de identificar o real interesse dos colaboradores, levando em consideração o sexo, faixa etária e área de atuação. A conscientização e incentivo dos gestores também contribuíram para a implementação e engajamento dos colaboradores.

\section{COMPARATIVO DE PARTICIPAÇÃO NAS AÇÕES DE QUALIDADE DE VIDA}

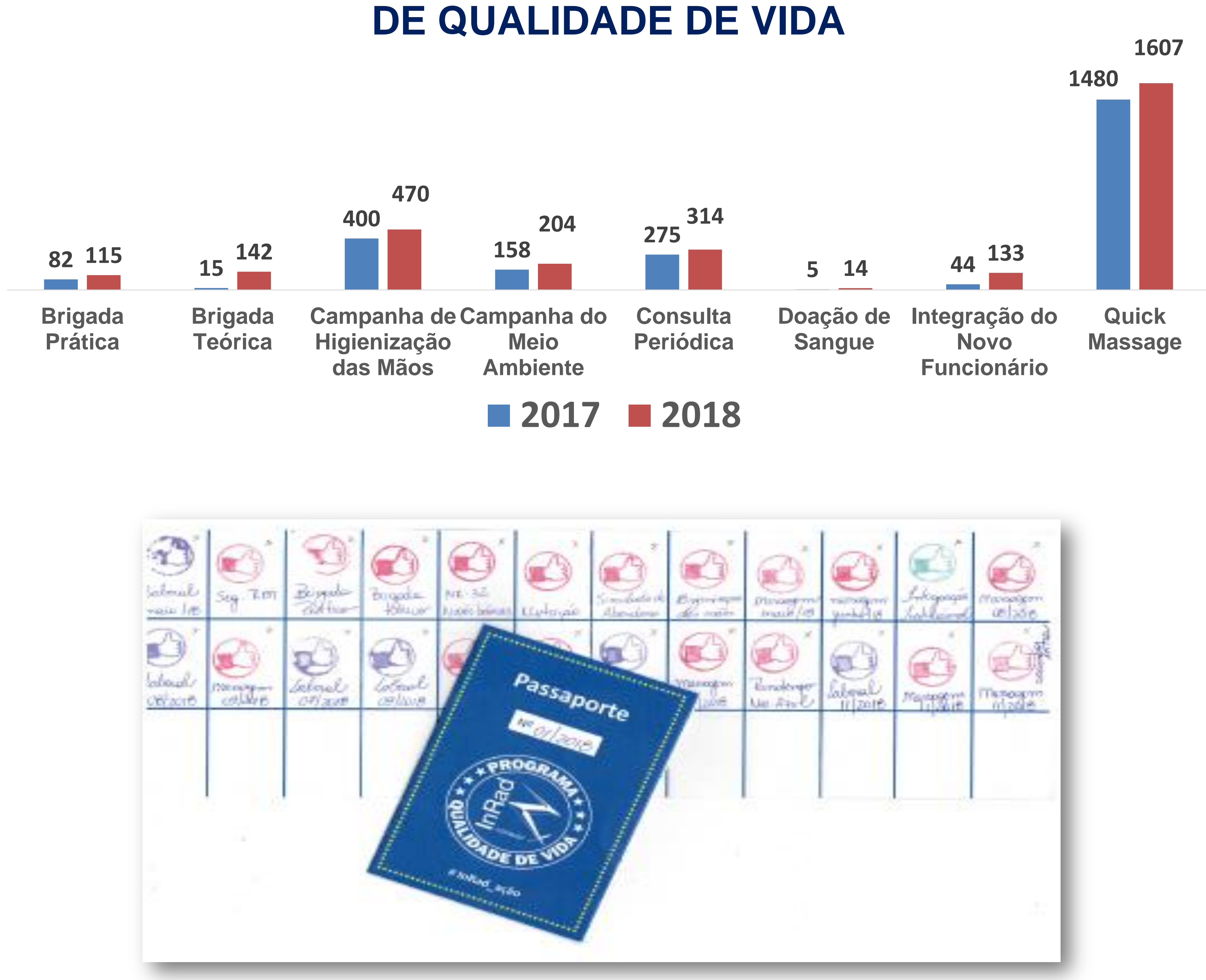

\section{Referências Bibliográficas}

1. Constantino, Maria Aparecida da Cruz (2012, p.23) - Revista Científica JOPEF, Vol.13 - n 2 Ano 9 / 2012 